\title{
Cardio protected areas in Mexico
}

\section{Áreas cardioprotegidas en México}

\author{
Agustín R. Urzúa-González¹, Manuel J. Rivera-Chávez²*, Reynaldo Zapién-Villegas ${ }^{3}$ y \\ Pedro A. Huaracha-López \\ ${ }^{1}$ Unidad de Cuidados Intensivos Coronarios; ${ }^{2}$ Unidad de Terapia Intensiva; ${ }^{3}$ Medicina Interna Hospital Regional de Alta Especialidad del Bajío; \\ ${ }^{4}$ Departamento de Medicina y Nutrición. Universidad de Guanajuato, León, Guanajuato, Mexico
}

\begin{abstract}
Sudden cardiac death $(S C D)$ remains a major public health problem. Fortunately, with timely access to early defibrillation and high-quality cardiopulmonary resuscitation, an improvement in survival of victims of sudden death has been demonstrated. Efforts made in different countries to create programs for access to public defibrillation have shown great benefits in counteracting mortality associated with this type of event. Hence, we need more programs (such as cardio protected environments) and changes in public health policies. The objective of this work is to raise awareness among the population and decision makers, of importance establishing this type of programs in our country since there continues to be high mortality associated with SCD in our countrymen.
\end{abstract}

Key words: Cardio protected areas. Defibrillation. Sudden cardiac death.

\section{Resumen}

La muerte súbita cardíaca es todavía un problema importante de salud pública. Por fortuna, con un acceso oportuno a una desfibrilación temprana y una reanimación cardiopulmonar de alta calidad, se ha demostrado una mejoría en la sobrevida de las víctimas de muerte súbita. Los esfuerzos realizados en deferentes países para crear programas de acceso a la desfibrilación pública han mostrado grandes beneficios en contrarrestar la mortalidad relacionada con este tipo de episodios. Se necesitan más programas (como espacios cardioprotegidos) y cambios en las políticas de salud pública. El objetivo de este trabajo es poder concientizar a la población y a los tomadores de decisiones de la importancia de establecer este tipo de programas en el país, ya que aún existe una alta mortalidad relacionada con la muerte cardíaca súbita.

Palabras clave: Áreas cardioprotegidas. Desfibrilación. Muerte súbita cardíaca.

\section{Correspondence:}

*Manuel J. Rivera-Chávez

E-mail: rivera.ug@outlook.com
Date of reception: 12-03-2019

Date of acceptance: 23-07-2019

DOI: 10.24875/ACM.19000158
Available online: 13-09-2019 Arch Cardiol Mex (Eng). 2020;90(2):207-215 www.archivoscardiologia.com 1405-9940/C 2019 Instituto Nacional de Cardiología Ignacio Chávez. Published by Permanyer. This is an open access article under the CC BY-NC-ND license (http://creativecommons.org/licenses/by-nc-nd/4.0/). 


\section{Introduction}

Out of hospital cardiac arrest is a serious health problem in the world and in Mexico. In 2004, it was estimated that sudden cardiac death (SCD) represented 33-53 thousand deaths per year in our country ${ }^{1}$. However, there are not an accurate data, mainly due to the lack of reporting of such events. A patient who has been a victim of cardiac arrest outside of a hospital strictly depends on the rapid action of a first responder, who recognizes the event and activates emergency medical services (EMS), provide a quality cardiopulmonary resuscitation (CPR), and receive a faster shock with automatic external defibrillator (AED), to increase probabilities of survival' ${ }^{1}$.

This series of events collaborates extensively in improving the probability of survival, with better neurological recovery after the event, in victims of SCD. Cardiac protection programs aim to have an area in which an AED is available to be used in case of cardiac arrest, as well as personnel trained in CPR and use of these devices; to achieve the patient with AED in < 4-5 $\mathrm{min}^{1}$.

In Mexico, records and analysis of a cardiac protection program in the township of San Miguel de Allende, Guanajuato2; are the only source available, which represents the first initiative in documenting of these kinds of projects. Nevertheless, public access of defibrillation programs and training in CPR maneuvers has been launched in some other states of our country; as well as reforms or initiatives to change the health law, which that should be mandatory to have AED in highly crowded places where more than 500 people are concentrated ${ }^{3}$.

Due to the relatively recent initiative of politics to implement programs, it is not yet possible to evaluate its effect on the Mexican population, but it is possible to find out most suitable locations for future placement of AED. It is also essential to implement CPR training campaigns for the general population in order to further collaborate with the culture of resuscitating SCD victims ${ }^{4}$.

\section{How we define cardiac protection?}

Cardiac protection can be defined as the ability to respond promptly and adequately, with the necessary maneuvers and equipment, in a scenario of a sudden cardiac arrest, to provide initial help to individuals who are victims of an SCD, before the arrival of EMS to the victims.
Clinical practice guidelines of our country, estimate that in the world, each year, there are more than 135 million deaths due to cardiovascular causes; coronary disease being the most important. Out-of-hospital cardiac arrest is a very important public health problem. Worldwide, there are approximately 420,000 cases annually in the United States and 275,000 in Europe'. In Mexico, in 2004, the incidence of sudden death was estimated, between 33 and 53 thousand deaths per year ${ }^{5}$.

The main reason for lack of information regarding cardiac arrest and deaths associated with it in our country is that, although SCD has an international disease code, it can be found with three different options: cardiorespiratory arrest, ventricular fibrillation (VF), and cardiac arrhythmia not specified; none of these is used in Mexico in death certificates; situation that conditions its non-accounting ${ }^{6}$. However, in reference of the statistical exercise done by Rodríguez-Díez with public data from the National Institute of Statistics, Geography, and Informatics (INEGI) of 2009, we can update them and observe that in 2016 there were 685,763 total deaths in Mexico, of which 175,078 were due to circulatory system disease and 103,326 were presented outside from the hospital (public road, home, and places not specified). When analyzing the number of deaths outside the hospital that did not receive medical attention $(23,233)$ and assuming as in the statistical exercise homologous, we found that this number of sudden deaths of cardiac origin, being of the circulatory system. This represents $13.26 \%$ of deaths due to circulatory causes and $3.4 \%$ of total mortality; almost equal to $3.55 \%$ calculated in 2009 .

It is important to highlight the poor prognosis that affected patients who suffer an SCD, when early defibrillation is not provided, in a scenario of a shockable rhythm: VF and ventricular tachycardia (VT) without pulse. It has been described in multiple series that for every minute delayed defibrillation, there is a $10-12 \%$ decrease in the probability of survival at hospital discharge, with CPR as a mitigating factor for this percentage, reducing it to $3-4 \%$ per minute without defibrillation ${ }^{7-9}$.

Three phases have been described, when cardiac arrest occurs, in relation to the findings in the patients and the effect that each of different therapeutic strategies would have on each phase:

1. Electric phase: first $4 \mathrm{~min}$; during this time direct defibrillation would be the most effective treatment.

2. Circulatory phase: between next 4 and $10 \mathrm{~min}$; during which CPR shows greater effectiveness. 
3. Metabolic phase: after $10 \mathrm{~min}$; treatment should focus on cardiac and systemic metabolic alterations ${ }^{10}$.

Therefore, timely defibrillation in the first $4-5 \mathrm{~min}$ is highly effective, using CPR to increase its effectiveness. It should be noted that although CPR is essential to increase the window period in which defibrillation is possible, when it is not immediately available, it is in itself inefficient, since it only contributes $10-30 \%$ of the normal blood flow to heart and between 30 and $40 \%$ of normal flow to brain, highlighting the need to adequately perform the technique ${ }^{11}$. It has also been seen that this technique is up to $40 \%$ more effective if it is carried out by trained personnel.

Survival rates in patients who had extra hospital cardiac arrest on discharge from the hospital range from $0.2 \%$ in Detroit, $1.8 \%$ in Chicago, $2.2 \%$ in New York, $33.7 \%$ in Arizona, and $3.3 \%$ in Chile. In Mexico, it was reported in the city of Querétaro, after examining 3 cases of cardiac arrest (2 of which occurred in the victim's home and one remaining in a commercial place), a hospital discharge survival of $0 \%{ }^{12}$. In contrast, a study in the city of Monterrey, in which 139 cases of cardiac arrest were analyzed, reported survival to hospital discharge of $31.25 \%$ (10 patients), a group in which the resuscitation time was $<9$ min in $80 \%$, and in $20 \%$ it was $<5.2 \min ^{13}$.

The survival rate is a direct function of the ability of a first responder to initiate CPR maneuvers and activate the emergency system to request arrival of an EMS team, trained for such events, to incident place; likewise, time between collapse and arrival of EMS, and between collapse and defibrillation. Place where the cardiac arrest occurs is also important, since there is a higher survival rate if it occurs on public roads, compared to one that occurred in a private home.

\section{What is defibrillation?}

It consists of the use of electric shock, for short periods of time, to depolarize the myocardium, ending with a VF or another arrhythmia, to recovering adequate cardiac electrical activity. This therapeutic alternative is the only effective treatment of VF or pulseless VT. $V F$ is the most frequent initial rhythm in cardiac arrest; it progresses to asystole in a few minutes if it is not reversed early, reducing the possibility of survival, since asystole is not a shockable rhythm.

Before the classification of defibrillators, following concepts must be taken into consideration:
- A defibrillation discharge passes a flow of electrons through the heart; this flow is called shock, which is measured in amperes (A).

- The push pressure of electron flow is called electrical potential and is measured in volts $(\mathrm{V})$.

- The resistance that exists to flow of electrons is called impedance, is measured in Ohms $(\Omega)$, and is determined by factors such as: selected discharge energy, size of the electrodes, electrode-skin coupling material, distance between electrodes (size of chest), and contact pressure.

To reduce impedance (allowing an optimal passage of electrons on heart) operator press firmly pallets or properly place electrodes of AED, as well as use a gel or cream in patient's chest. The size of the electrodes likewise influences impedance, a size of $8.5-12 \mathrm{~cm}$ diameter is recommended for adults, and smaller electrodes should be used in children and infants. The position of electrodes should be as follows:

- To the right of the upper side of sternum below clavicle and

- To the left of nipple line with the center of the middle axillary line $e^{14}$.

\section{What is a defibrillator?}

It is a portable device, which administers a controlled electric shock to patient, to end with cardiac arrhythmia. Modern defibrillators are classified into two types, according to waveform: monophasic and biphasic.

Monophasic defibrillators deliver current of one polarity (energy that flows in one direction), main disadvantage is that the amount of energy delivered varies with transthoracic impedance and size of patients.

Biphasic defibrillators deliver current in two phases: initial (2/3 of time) in a positive direction, which, in a second phase (final $1 / 3$ ) at a certain interval, reverses its initial direction abruptly.

Evidence from studies indicates that biphasic wave shock is equally or more successful in terminating a VF than in single-phase shock ${ }^{15}$. Defibrillation requires enough electrical energy to defibrillate a critical mass of myocardium, abolish VF and restore synchronized spontaneous electrical activity in the form of an organized rhythm. The recommended dose is $360 \mathrm{~J}$ for monophasic defibrillators, and between 120 and $200 \mathrm{~J}$ for biphasic defibrillators, if second or additional defibrillation is necessary, it is recommended that it be at least one energy level equivalent to or greater than previous one. 


\section{Cardiac protection in the world}

The implementation of a cardiac protection system has been documented in large studies, such as the Girona protected area project, and a Brazilian study where the use of AED was implemented in the collective system of the Metro. In a Swedish study, which analyzed early extra-hospital CPR; among others, they have shown the effectiveness of these devices in the reduction of mortality in victims of cardiac arrest.

In the Girona cardiac protected area project, which lasted 48 months $^{16}, 747$ AED were distributed in this province, covering a density of 1 AED per 1,000 inhabitants, and indirectly in cases where CPR was administered quality of these maneuvers, according to electrocardiographic traces obtained by AED. There was a total of 231 activations with a predominance of mobile AED use (76\%) compared to a fixed AED (24\%), intermediate to correct use was given in $97 \%$ of cases and a complete record of 188 activations, in which predominance of mobile against not mobile AED use was maintained at $82 \%$ and $18 \%$, respectively. A total of 98 shocks were administered with an average of 2.4 per patient, obtaining the reversion of the arrhythmia in $85.4 \%$ of shockable rhythms (47), it was observed according to electrocardiographic tracings that CPR was performed in $80.1 \%$ of cases (152) being considered correctly applied only in $51.9 \%$ (79 cases), finally 46 of the 47 patients with shockable rhythms where receive medical aid in proper way according to guides; however, the survival at hospital discharge and the final neurological function of patient were not considered in this study ${ }^{16}$. These patients, it should also be noted that after analysis of electrocardiographic tracings obtained and reviewed by expert cardiologists, it was determined that sensitivity of these devices was $82.9 \%$ (attributable to low sensitivity ${ }^{33 \%}$ ] in the detection of fine wave VF. $89 \%$ for thick-wave PV) and a specificity of $100 \%{ }^{16}$.

The Brazilian study of implementation of a public defibrillation program in metropolitan transport collective system in the city of Sao Paulo ${ }^{17}$, split into two periods: an initial one of 16 months that were used as "initial experience" to have an overview of how it could have been before the establishment of this program since there were no previous studies in this regard, and a $2^{\text {nd }}$ time, which covered the remaining 5 years. For this project, security guards of the Sao Paulo Metro were trained in the use of AED and in CPR, in accordance with guidelines of the AHA (American Heart Association) from 2005 to December 2010 ${ }^{17}$. As of January In 2011, information on these elements was updated with the new 2010 AHA guidelines. An AED was installed in each of the 58 stations of the transportation system, and a binaries system was implemented to speed up the response in case of presenting a stoppage event, as well as the use of surveillance cameras for quick detection of these events.

This study reported a total of 102 collapses, of which 86 had a confirmed cardiac arrest, no subject whose initial heart rhythm was not reversed survived to hospital discharge, 62 subjects had an initial rate of VF, and of these only $37 \%$, they survived the hospital discharge and 1 year after event, with minimal neurological deterioration. Those who survived had a characteristic of younger age and shorter collapse-CPR interval; differences found between two periods of this protocol were in the long-term results: survival to hospital discharge and favorable neurological results, as well as 1 -year survival ${ }^{17}$. When they compared this study with one performed in the city of Belo Horizonte, from a total of 1165 cardiac arrests: nearly $67 \%$ that could be investigated final neurological function, contrasts $1.1 \%$ of good brain function after collapse, against obtained in the study of Sao Paulo metro ${ }^{17}$.

\section{Public access defibrillation programs in Mexico}

In Mexico, extra-hospital cardiac arrest and response by EMS have been studied in a few series, as well as variables that can derive from these events, such as survival at different time intervals and post-stop neurological functionality. There is only one public access documented defibrillation program: "San Miguel Seguro"2 in San Miguel de Allende, Guanajuato; which consisted of a three-stage project with compliance in 2 years:

1. Training to EMS, and others that could act as first responders: red cross, Municipal Civil Protection, firefighters, police, and transit police. This thorough training and certification of instructors who replicated the training to health staff

2. Placement of 6 AED, obtained as a donation, in locations where there were subjects with susceptibility to be used, and training in hospital units on the survival chain

3. Training of schools, nurseries and the general public on the use of $A E D$, achieving a training of just over 1200 people, under training by brigade members in basic life support in "Save hearts" modality.

The program "San Miguel Seguro"2 presents start-up of a public access defibrillation program, promoting 
education in CPR and use of AED in possible first responders. However, the effect of this program on out-of-hospital cardiac arrest care was not evaluated since it was considered by authors that more time is required (5-10 years) to be able to obtain results on it. Despite this, it was possible to observe how ambulances of the red cross that has AED was used in services they provide, obtaining a survival rate at hospital discharge of $50 \%$ in 4 cases treated until the writing of such work ${ }^{2}$.

In addition to this effort to promote cardio protected spaces, following states have a report on implementation of public defibrillator access programs, which, although they do not report implementation and/or results obtained through a scientific dissemination article, as in case of "San Miguel Seguro" project, its implementation is verified in different journalistic media of country:

- Mexico City: Forty AED ${ }^{18}$ was installed in busiest subway stations, since November 9, 2016; a pilot program four paramedics ${ }^{19}$ was implemented on motorcycles equipped with AED to attend cardiac medical emergencies in areas of difficult access in highlands Magdalena Contreras Delegation (June 17, 2017); 7 "life towers," widely equipped, were placed for response to cardiac arrest in Cuauhtémoc Delegation $^{20}$ (September 22, 2016); In Carso square, 25 people were trained in CPR maneuvers, and AED was placed for public use ${ }^{21}$ (October 14, 2015).

- Jalisco 10 cardiac protected areas ${ }^{22}$ (January 2, 2018): (1) Chapultepec walker, (2) State Government Palace, (3) Jalisco Secretary of Health headquarters, (4) State Health Councils, (5) High School 10 of University of Guadalajara, (6) Congress of the State of Jalisco, (7) Municipal Services of Tlajomulco de Zúñiga, (8) Regulatory Council of Tequila, (9) Casa Herradura, and (10) Hotel Gran Velas. ${ }^{22}$

- Nuevo León: Municipality of San Pedro Garza García, on November 25, 2014, 5 "life towers" were installed, equipped with AED, for a timely response to cardiac arrest. ${ }^{23}$

- Puebla initiated the strategy: "Puebla, cardiac protected state" (April 7, 2017), with the installation of 23 fixed modules of AED in 20 municipalities of this state, in an effort shared with the Society of Interventional Cardiology of Mexico. ${ }^{24}$

- Querétaro (October 5, 2017): Expects to reach 20 thousand people trained in first aid and CPR; likewise, it acquired 93 AED that will be placed in strategic points and public places of great affluence, as well as patrols and motorcycles patrols. ${ }^{25}$
- Sonora has three townships with cardiac protected areas programs: ${ }^{26}$ Hermosillo (1 AED), and Caborca and San Luis Río Colorado (4 AED). It also has a cardiac protection law approved in May $2017^{3}$.

- Tamaulipas: It has certified cardiac protected buildings and public areas: Tamatán Zoo, Federal city hall and the IPSSET Gymnasium; and some more in the process of certification: Bicentennial Tower, Rector of the Autonomous University of Tamaulipas, Ministry of Health and Supreme Court of Justice. All these places have AED (April 27, 2016) ${ }^{27}$.

- Yucatan has five cardiac protected areas: A shopping center (the large square), International Airport of Mérida (Manuel Crescencio Rejón), city hall of Mérida, State Congress, Costa Club hotel of ISSTEY; sites that have been equipped from June 8, 2016, to March 1, 2018, with AED ${ }^{28}$.

There are isolated efforts in search of having cardiac protected areas and events, such as the one undertaken by the Autonomous University of San Luis Potosí, which has three AED within its facilities since December $2015^{29}$, as well as Tangamanga Park ${ }^{30}$ where there is also an AED, or half marathon ${ }^{31}$ held on September 22,2016 , which was cardiac protected, and was available, in case of eventualities of 2 AED, one at the beginning of the journey and another at $10 \mathrm{~km}$. In the city of León, Guanajuato, two editions of city marathon (2016 and 2017) were cardiac protected ${ }^{32}$.

Despite efforts mentioned here on cardiac protection, there is no study of the results of such programs so that it is currently not possible to measure the effectiveness of them, this may be because they are recent programs, so it will be necessary to wait some years.

\section{Where to place AED?}

There are studies that can be taken as a basis to implement optimization systems in the placement of AED in cities, as observed in Stockholm county ${ }^{33}$, between January 1, 2012, and December 31, 2014; there were 804 out-of-hospital cardiac arrests, with 1828 AED available to respond to these cases. This study reports an incidence of cardiac arrests in residential areas similar to that observed in non-residential areas (47.3\% vs. $43.4 \%$ ), on the other hand, fewer AED was present in residential areas compared to non-residential areas $(29.4 \% \text { vs. } 68.8 \%)^{33}$, contributing to a greater AED-cardiac arrest distance in residential areas $(288 \mathrm{~m}$ vs. $188 \mathrm{~m}$ ). Despite the increase during the past decade in the number of AED in such a region, it is still under report of its use $1.7-12.8 \%{ }^{33}$. 
Central point of this study was use of a digital urban atlas based on satellite images (available throughout Europe), as well as Swedish AED (SAEDREG) registry that allowed to classify city into two large areas: residential and non-residential, which in turn were divided according to decreasing density of residences and factories for Group 1 (forming 6 subgroups) ${ }^{33}$, and according to increasingly wide land extensions destined to green areas, sports clubs or water bodies for Group 2 (forming 4 subgroups) $)^{33}$. The results, after including in these areas cardiac arrests and (theoretical) availability of registered $A E D$, indicated that the highest number of cardiac arrests did not correspond to the highest proportion of AED in Group 1 ([cardiac arrests in residential areas] $27 \%$ of cardiac arrests in subgroup 3 of Group 1 and $11 \%$ of availability of AEDs in this same subgroup), with an adequate agreement for Group 2 (65\% of cardiac arrests in subgroup 1 of Group 2 and $86 \%$ of availability of AED in this same subgroup ${ }^{33}$.

In this study, there was a greater incidence of cardiac arrests in areas of medium and low density of residences, in comparison with more densely populated areas; similar results were found in other series, being convenient, therefore, an analysis of this type (geographical), for the planning of placement of AED, as well as for their possible relocation ${ }^{33}$.

Geographical studies are very useful for planning the placement of AED in strategic locations. However, adding real availability of such devices could improve an event of cardiac arrest, as demonstrated in a study from the city of Toronto, Ontario, Canada ${ }^{34}$, where there was a loss heart recovery by AED of $21.5 \%$; of the 451 cardiac arrests, located $100 \mathrm{~m}$ from a registered AED. only 354 had real coverage, influenced mainly by the time at which the event occurred, the location (center or periphery of the city) and day of the week (the AED application was lower on weekends vs. the rest of the week: 6.2 vs. $11.2 \%)^{34}$. From a total of 737 AED locations, 542 (73.5\%) were not open $24 \mathrm{~h}$, and 211 (28.6\%) were closed on weekends. When the deployment of AED was optimized, using a spatiotemporal model, a relative increase of $25.3 \%$ in coverage was obtained, equivalent to a requirement of $32.3 \%$ lower AED, to cover the same number of cardiac arrests, compared with the model that did not consider time ${ }^{34}$.

The placement of AED in buildings has also been studied, and its repercussion in the survival of patients, as in case of federal buildings in the United States, where Federal Occupational Health, performs a public access defibrillation program. This study analyzed a database of such an organization from 1999 to 2012, which includes a total of 1000 locations in this country, in which 3250 AED is distributed ${ }^{34}$. There was a total of 132 episodes where an AED was involved; only $73 \%$ (96 patients) were of cardiac etiology, and of these: nearly 67 were witnessed, but only 54 had a shockable rhythm. In this group, a survival rate at hospital discharge of $39 \%$ (21 patients) was obtained; in the rest of the patients (29) in whom cardiac arrest was not observed, a discharge with AED was administered to only 12 patients, obtaining a survival of $6.8 \%$ (2 patients). The first responders-initiated CPR maneuvers in $93 \%$ of the cases, and those cases in which an AED was used and indicated by this, the need for defibrillation was administered in $91 \%$ of the patients. The mean interval between collapse and arrival of a first responder was 3 min (range: 1-22 min) and mean interval between collapse and first shock was $5 \mathrm{~min}$ (range: 3-23 min). In this study, the greatest survival could be observed for cases in which cardiac arrest was observed, versus those that were not, as well as a high percentage of CPR initiation; this can be explained by the training employees of such buildings had, as well as the implementation of periodic drills. Finally, it was observed that the highest number of cardiac arrests occurred in work spaces (46\%) against other sites (public areas, parking lots, bathrooms, and outdoor places) ${ }^{34}$.

\section{Mexican legislation regarding cardiac protection}

In Mexico, there are only two states (Sonora and Jalisco) with approved laws, which mention obligatory of the provision of AED:

- General Health Law of the State of Jalisco, it is mentioned in Chapter VIII (Public Health), Article 78 Bis: "In any public or private building that generates concentrations of at least 500 people, it must be available to the public, at least one AED; being meritorious to sanction (temporary or definitive, partial or total closure of the offending establishment) the non-compliance of the previously arranged, indicated thus in Chapter II (Of the administrative sanctions)," Article $252^{35}$.

- On the other hand, Law 186 of cardiac protection for the State of Sonora, specifies in Chapter II, Article 4, which will be considered cardiac protected areas or territories, those properties or public and private events, where a thousand people or more will be concentrated; nothing that in these spaces, at least one AED must be installed, having as a sanction the closure or non-completion of event, as appropriate, 
if an AED is not available. It is also mentioned in Chapter III, that in all townships of this state, there should be at least one AED placed in front of the health centers or places of high concurrency. Finally, Chapter IV shows the null civil or administrative criminal liability that could be imputed to the person who provides CPR to a person after a cardiac arrest ${ }^{25}$.

Although only two states have laws of this magnitude, it should be noted that in some states reform initiatives have been proposed to the Health Laws, to achieve the implementation of Laws such as those previously stated; this in the States of Chiapas (October 4, 2016), Coahuila (May 10, 2016), and State of Mexico (June 4, 2014).

\section{Proposed certification of cardiac protected areas in Mexico}

In the presence of SCD out of hospital, only $5 \%$ of patients survive. However, if receives adequate basic CPR and early defibrillation by means of an AED, within the $1^{\text {st }}$ min of the collapse, survival rates may increase by $74 \%$ or more 1 .

And in accordance with international standards, and the Spanish Society of Medicine and Safety at Work (in Spanish, Sociedad Española de Medicina y Seguridad en el Trabajo, SEMST), which is responsible for certifying as "cardiac protected areas," buildings, hospitals, sports clubs, etc.

We consider that an adequate cardiac protected area, to expedite the performance of personnel working in these spaces in the timely care of an SCD victim with access to electrical defibrillation and high-quality CPR maneuvers in less than $5 \mathrm{~min}$.

Therefore, our evaluation cards do not only consider the physical requirements, such as the number of AED needed to cover a temporary radius of $2 \min 30 \mathrm{~s}$. It also includes periodic drills to keep trained personnel alert to any SCD event that occurs in their facilities.

\section{Discussion}

Although ischemic cardiopathy leads as the main known cause of SCD, this is not the only cause of SCD, recently in 2017; an observational, descriptive, comparative, cross-sectional study was carried out ${ }^{36}$. Information was gathered on the number of sudden cardiovascular deaths occurred during the years 20052010, for each state of the Mexican Republic, through the consultation of the database of the INEGI. With the data obtained, the states of the Mexican Republic were mapped, through the use of crude rates, states of northern border strip were located with low and medium-low rates, and only one of them with a high rate, Federal District (recently named Ciudad de Mexico). After standardization, entire northern border strip was located between medium-high and high; rest of the country was also at a higher level in its rate, except from two states located to the south, Quintana Roo and Chiapas ${ }^{36}$.

This information is valuable to determine the states of the country where place AEDs. Furthermore, other causes of sudden cardiovascular deaths such as cardiomyopathies who incidence is unknown. As with other diseases, authorities depend on reported cases (at necropsy or as a part of clinical disease coding) to define the prevalence and incidence rates. The inconsistency in nomenclature and disease coding classifications for cardiomyopathies has led to collected data that only partially reflect the true incidence of these diseases ${ }^{37}$.

Whether secondary to improved recognition or other factors, the incidence and prevalence of cardiomyopathy appear to be increasing. The reported incidence is $400,000-550,000$ cases per year, with a prevalence of 4-5 million people ${ }^{37}$.

Cardiomyopathy is a complex disease process that can affect the heart of a person of any age, and clinical manifestations appear most commonly in the third or fourth decade ${ }^{37}$. Moreover, as we know, it is also a cause of SCD.

Another cause of SCD like Chagas disease caused by Trepanosoma cruzi is endemic in Mexico and all the countries of Central America and South America. In 2016, the World Health Organization estimated that a total of 6-8 million people are infected with T. cruzi and that about 12,000 deaths each year can be attributed to Chagas disease ${ }^{38}$. To give a country-specific perspective on the relative prevalence rates, in 2007, PAHO published the following data regarding the countries most affected by Chagas disease: Bolivia (6.8\% prevalence); Argentina (4.1\%); El Salvador (3.4\%); Honduras (3.1\%); Paraguay (2.5\%); Guatemala (2\%); Ecuador (1.7\%); French Guyana, Guyana, and Surinam (1.2\%); Venezuela (1.2\%); Nicaragua (1.1\%); Brazil (1\%); and Mexico $(1 \%)^{39}$.

Use of AED in cardiac arrest events, implemented in public areas of high population concentration, unquestionably show better benefits, which can be further expanded with the application of high-quality CPR, and promptness in activation of the survival chain.

It has been proposed in a study that training in CPR, use, and equipment with AED, of elements of the police force, could increase the response rate to cardiac 
arrest since it has been seen that in $64 \%$ of cases a police vehicle arrives earlier at the place of cardiac arrest, compared to ambulances ${ }^{40}$. It has been shown that there are factors that influence the use of AED or by bystanders such as the academic grade, characteristics of the population and whether there are people who live alone or not ${ }^{41}$. Hence, the decision of where to place them should be based on aspects like these.

There is no doubt that the adequate implementation of programs that allow early defibrillation in case of public out-of-hospital cardiac arrest has shown that it improves the possibility of survival in patients as reported by Pollack, et al. ${ }^{42}$ Even these policies to ensure cardio protected scenarios should be part of state and national health programs. Without forgetting to have an adequate record of cases in which these were used to continue having continuous improvement and feedback on how and when they were employed ${ }^{43}$.

The programs, in Mexico on cardiac protection, are therefore the first initiative with a wide potential for studying the effect of these programs on the survival of those who benefit from CPR maneuvers and early defibrillation (if necessary); so, design of protocols for their documentation would be extremely useful. We must also consider the relatively new nature of these programs, so it is still early to obtain concrete results.

Finally, the health concern in considering the great problem that the SCD represents has led to the implementation of laws so that cardiac protection in places and widely attended events is possible. However, these laws are limited to a couple of states so that the adoption of these measures by the rest of the states of the Mexican Republic would also help to improve the survival of those suffering from out-of-hospital cardiac arrest.

\section{Conflicts of interest}

The authors declare that there are no conflicts of interest in this project.

\section{Funding}

The authors declare that there was no type of financing in this project.

\section{Ethical disclosures}

Protection of human and animal subjects. The authors declare that no experiments were performed on humans or animal for this study.
Confidential of data. The authors declare that they have followed the protocols of their work center on the publication of patient data.

Right to privacy and informed consent. The authors declare that no patient's data appear in this article.

\section{Addendum}

The authors do not consider necessary graphics or tables for the correct understanding of this text

*Special thanks to the Dr. José Daniel Rivera-Sandino for his invaluable cooperation for the translation of this article into the English language.

\section{References}

1. Hasselqvist-Ax I, Riva G, Herlitz J, Rosenqvist M, Hollenberg J, Nordberg $P$, et al. Early cardiopulmonary resuscitation in out-of-hospital cardiac arrest. N Engl J Med. 2015;372:2307-15.

2. Hernández NA, Regalado JF, Hall H, Vázquez LG. San miguel seguro, experiencia latinoamericana en la implementación del programa de desfibrilación de acceso público. Arch Med Urgenc México. 2013;5:53-9.

3. Ley Número 186 de Cardioprotección Para el Estado de Sonora. Boletín Oficial de Sonora México. (02 Mayo 2017). Available from: http://www. boletinoficial.sonora.gob.mx/boletin/images/boletinesPdf/2017/mayo/ 2017CXCIX35III.pdf. [Last accessed on 2018 Aug 15].

4. Sun CL, Demirtas D, Brooks SC, Morrison LJ, Chan TC. Overcoming spatial and temporal barriers to public access defibrillators via optimization. J Am Coll Cardiol. 2016;68:836-45.

5. Asensio E, Narváez R, Dorantes J, Oseguera J, Orea TA, Hernández RP, et al. Conceptos actuales sobre la muerte súbita. Gac Méd México. 2005; 141:89-98.

6. Rodríguez-Diez G. Importancia de un sistema de atención integral en la recuperación del paro cardio-respiratorio. Arch Cardiol México. 2014;84:84-5.

7. Rodríguez RH, Muñoz GM, Márquez MF, Pozas GG, Asensio LE, Ortiz GF, et al. Muerte súbita cardiaca. Estratificación de riesgo, prevención y tratamiento. Arch Cardiol México. 2015;85:329-36.

8. Medical Advisory Secretariat. Use of automated external defibrillators in cardiac arrest: an evidence-based analysis. Ont Health Technol Assess Ser. 2005;5:1-29.

9. Perkins GD, Handley AJ, Koster RW, Castrén M, Smyth MA, Olasveengen $T$, et al. European resuscitation council guidelines for resuscitation 2015: section 2. Adult basic life support and automated external defibrillation. Resuscitation. 2015;95:81-99.

10. Moya-Mitjans À, Lidón R. Desfibrilador externo automático en la muerte súbita extrahospitalaria: en busca del tratamiento eficaz. Rev Española Cardiol. 2018;71:64-6.

11. Meaney PA, Bobrow BJ, Mancini ME, Christenson J, de Caen AR, Bhanji F, et al. Cardiopulmonary resuscitation quality: improving cardiac resuscitation outcomes both inside and outside the hospital: a consensus statement from the American heart association. Circulation. 2013;128:417-35.

12. Fraga JM, Aguilera A, Barinagarrementería F, Ortiz C, Asensio E. Informe de 3 casos de reanimación extrahospitalaria en la ciudad de Querétaro: importancia de un sistema integral de atención de emergencias médicas. Arch Cardiol México 2014;84:79-83.

13. Cantú R, Fernández M, Mercado R, Pizaña A, Zamora J, González R, et al. Sobrevida y calidad de vida en pacientes con paro cardiorrespiratorio extrahospitalario en la ciudad de Monterrey, Nuevo León, México. Med Univ. 2012;14:145-9.

14. Corsiglia D, Ruiz WJ. Soporte vital avanzado (SVA) resucitación cardiopulmonar y cerebral de avanzada (RCPa o RCPCa). En: Corsiglia D, Ruiz WJ, editor. Reanimación Cardiopulmonar y Cerebral. $4^{\mathrm{a}}$ ed. Buenos Aires: Fundación UDEC; 2002. p. 137-45.

15. Lagos P. Desfibrilación. Rev Chil Anestesiol. 2012;41:28-35.

16. Loma $P$, Núñez M, Aboal J, Bosch D, Batlle $P$, de Morales ER, et al. Proyecto girona territori cardioprotegit: evaluación del funcionamiento de los desfibriladores públicos. Rev Española Cardiol. 2018;71:79-85.

17. Gianotto-Oliveira R, Gonzalez MM, Vianna CB, Alves MM, Timerman S, Filho RK, et al. Survival after ventricular fibrillation cardiac arrest in the Sao Paulo metropolitan subway system: first successful targeted automated external defibrillator (AED) program in Latin America. J Am Heart Assoc. 2015;4:e2185. 
18. Gómez-Flores L. Se atenderán en el Metro Casos de Ataques Cardiacos. La Jornada México. (09 Noviembre 2016). Available from: http://www jornada.com.mx/2016/11/09/economia/037n3cap. [Last accessed on 2018 Aug 15].

19. Páramo A. Contra Infartos, a Bordo de Moto; Programa Piloto. Excélsior México. (16 Junio 2017). Available from: https://www.excelsior.com.mx/ comunidad/2017/06/18/1170455\#view-1. [Last accessed on 2018 Aug 15].

20. Equipan a la Delegación Cuauhtémoc Para Reforzar Cultura de Protección Civil. Delegación Cuauhtémoc. El corazón de México. (22 Septiembre 2016). Available from: https://www.cuauhtemoc.cdmx.gob.mx/equipan-a-la-delegacion-cuauhtemoc-para-reforzar-cultura-de-proteccion-civil. [Last accessed on 2018 Aug 15].

21. Delgado D. Reconocen a Plaza Carso Como Espacio "cardioprotegido". El Universal México. (14 Octubre 2015). Available from: http://www.eluniversal.com.mx/articulo/metropoli/df/2015/10/14/reconocen-plaza-carso-como-espacio-cardioprotegido. [Last accessed on 2018 Aug 15].

22. Villaseñor T. Jalisco Cuenta con 10 Espacios Cardioprotegidos. El Informador México. (02 Enero 2018). Available from: https://www.informador. $\mathrm{mx} / \mathrm{jalisco/Jalisco-cuenta-con-10-espacios-cardioprotegi-}$ dos-20180102-0113.html. [Last accessed on 2018 Aug 15].

23. Notimex. En Nuevo León Crean "Torres de vida" Para Prevenir Muerte Por Infarto. UniRadioInforma.com México. (25 Noviembre 2014). Available from: https://www.uniradioinforma.com/noticias/salud/309144/en-nuevo-leoncrean-torres-de-vida-para-prevenir-muerte-por-infarto.html. [Last accessed on 2018 Aug 15].

24. Puebla Sigue. Con Tony Gali Puebla se Convierte en la Primera Entidad Cardioprotegida. Puebla.gob.mx México. (07 Abril 2017). Available from: http://www.puebla.gob.mx/prensa-y-comunicacion/ item/1000-con-tony-gali-puebla-se-convierte-en-la-primera-entidad-cardioprotegida. [Last accessed on 2018 Aug 15].

25. Boletín. Presenta MAV Ciudad Cardio Protegida. Municipio de Querétaro México. (05 Octubre 2017). Available from: http://www.municipiodequeretaro.gob.mx/boletin.php?id=821. [Last accessed on 2018 Aug 15].

26. Roman B. Es San Luis "Territorio Cardioprotegido". Tribuna de San Luis México. (25 Agosto 2017). Available from: https://www.tribunadesanluis.com.mx local/es-san-luis-territorio-cardioprotegido. [Last accessed on 2018 Aug 15].

27. Adame-García C. Victoria, Ciudad con Edificios Equipados Para Atender Infartos. El Cinco México. (27 Abril 2016). Available from: https://www. elcinco. $\mathrm{mx} / \mathrm{cd}$-victoria/victoria-ciudad-edificios-equipados-atender-infartos. [Last accessed on 2018 Aug 15].

28. Salazar J. Solo Existen seis Desfibriladores en Yucatán. Milenio México. (01 Marzo 2018). Available from: https://www.sipse.com/milenio/conoce-aparato-salvar-vida-paro-cardiaco-seis-yucatan-287140.html. [Last accessed on 2018 Aug 15].

29. Presentó la UASLP el Programa San Luis Cardio Protegido. La Jornada San Luis México. (01 Diciembre 2015). Available from: http://www.lajornadasanluis.com.mx/politica-y-sociedad/presento-la-uaslp-el-programa-san-luis-cardio-protegido. [Last accessed on 2018 Aug 15].

30. Rodríguez M. Donan Desfibrilador al Tangamanga uno. Pulso Diario de San Luis México. (28 Mayo 2017). Available from: http://www.pulsoslp. com.mx/2017/05/28/donan-desfibrilador-al-tangamanga-uno. [Last accessed on 2018 Aug 15].
31. Atletas Cardioprotegidos en el Medio Maratón Universitario. El Heraldo de San Luis Potosí México. (23 Septiembre 2016). Available from: http://www.elheraldoslp.com.mx/2016/09/23/atletas-cardioprotegidos-en-el-medio-maraton-universitario. [Last accessed on 2018 Aug 15].

32. Morales LO. Ultima Detalles Operativos el Maratón León 2017. Milenio México. (19 Septiembre 2017). Available from: http://www.milenio.com/ estados/ultima-detalles-operativos-el-maraton-leon-2017. [Last accessed on 2018 Aug 15].

33. Fredman D, Haas J, Ban Y, Jonsson M, Svensson L, Djarv T, et al. Use of a geographic information system to identify differences in automated external defibrillator installation in urban areas with similar incidence of public out-of-hospital cardiac arrest: a retrospective registry-based study. BMJ Open. 2017;7:e14801.

34. Kilaru AS, Leffer M, Perkner J, Sawyer KF, Jolley CE, Nadkarni LD, et al. Use of automated external defibrillators in US federal buildings: implementation of the federal occupational health public access defibrillation program. J Occup Environ Med. 2014;56:86-91.

35. Ley de Salud del Estado de Jalisco Vigente. Congreso. Available from: http://www.congresoweb.congresojal.gob.mx/BibliotecaVirtual/busquedasleyes/Listado.cfm\#Leyes. [Last accessed on 2018 Aug 15].

36. Medrano-Rodríguez JC, Mata-Calderón MG, Ramírez KY, Contreras FH, Muro-Casas F, Medrano-Cortés E. Standardization of rates for sudden cardiovascular death in Mexico, 2010. CorSalud. 2017;9:143-7.

37. Ponikowski P, Voors AA, Anker SD, Bueno H, Cleland JG, Coats AJ, et al.2016 ESC guidelines for the diagnosis and treatment of acute and chronic heart failure: the task force for the diagnosis and treatment of acute and chronic heart failure of the European society of cardiology (ESC) developed with the special contribution of the heart failure association (HFA) of the ESC. Eur Heart J. 2016;37:2129-200.

38. World Health Organization. Chagas Disease (American Trypanosomiasis). World Health Organization; 2016. Available from: http://www.who. int/mediacentre/factsheets/fs340/en. [Last accessed on 2019 Jul 17].

39. Salvatella R. Estimación Cuantitativa de la Enfermedad de Chagas en las Américas. Washington, DC: Pan American Health Association; 2006.

40. Aguilera-Campos A, Asensio-Lafuente E, Fraga-Sastrías JM. Análisis de la inclusión de la policía en la respuesta de emergencias al paro cardiorrespiratorio extrahospitalario. Salud Pública México. 2012;54: 60-7.

41. Andersen LW, Holmberg MJ, Granfeldt A, Løfgren B, Vellano K, McNally BF, et al. Neighborhood characteristics, bystander automated external defibrillator use, and patient outcomes in public out-of-hospital cardiac arrest. Resuscitation. 2018;126:72-9.

42. Pollack RA, Brown SP, Rea T, Aufderheide T, Barbic D, Buick JE, et al. Impact of bystander automated external defibrillator use on survival and functional outcomes in shockable observed public cardiac arrests. Circulation. 2018;137:2104-13.

43. Fredman D, Ringh M, Svensson L, Hollenberg J, Nordberg P, Djärv T, et al. Experiences and outcome from the implementation of a national Swedish automated external defibrillator registry. Resuscitation. 2018;130:73-80. 